Die von dem schwefelsauren Blcioxyde geschiedene Flüssigkeit wurde mit kohlensaurem Natron übcrsältigt, bis fast zur 'Trockne verdunstet, die Masse mit 95 grädigem Weingeist behandelt, und der filtrirte geistige Auszug verdunstet, wobei $2,050 \mathrm{~g}$. Glycerin hinterblieben.

Das Präparat enthält mithin in 100 Gewichtstheilen:

1,56 Bleizucker.

2,01 Schwefel.

20,50 Glycerin.

75,93 Lavendelspiritus.

100,00 .

Wir haben also hier, trolz Marquart's Gegenversicherung, ein bei dauerndem Gebrauch höchst gefälirliches Haarfärbcmittel vor uns; es wäre daher Iflicht der Leipziger Apotheker, welchen vorstehende Notiz zu Gesicht kommt, die dortigo Polizei sofort auf jenen gewissenlosen Handel (der, da die Flasche $20 \mathrm{Ngr}$. kostet, auch noch eine Geldprellerei einschliesst, indem der Inhalt sammt Glas mit 4 Ngr. reichlich bezahlt ist) aufmerksam zu machen.

\title{
Wirkung des Wassers auf das Blei.
}

\author{
Von Raland.
}

(Aus den Compt. rendus, Febr. 1874, t. LXXVIII, p. 392.)

(Eingesandt von Wittstein.)

Bekanntlich weiss man schon sehr lange, dass das Blei von lufthaltigem Wasser angegriffen wird, indessen hat eine mehr als 20 Jahrhunderte lange Erfahrung gezeigt, dass man die mit bleiernen Röhren in Berührung gestandenen natürlichen Wässer obne Nachtheil trinken kann.

Beim Forschen nach dieser Unschädlichkeit hat man gefunden, dass die Anwesenheit sehr kleiner Mengen gewisser Salze es ist, welche den lösenden Einfluss des Wassers auf das Metall verhindert. 
Wie wirken nun diese Salze? Verhindern sie die Oxydation des Metalles oder bilden sie mit dem oxydirten Metalle eine Verbindung, welche weder fähig ist, sich in Wasser zu lösen, noch sich darin zu vertheilon? Diese Frage habe ich durch die nachstehenden Vorsuche zu beantworten gesucht.

I)ie perlmutterïhnliche Substanz, welche sich in Berührung des Bleies mit lufthaltigem Blei in bedeutender Menge crzeugt, ist nichts als reines Bleiweiss. Aeltere Versuche haben mir wiederholt ergeben, dass sie in der That auf 4 Aequiv. Bleioxyd 3 Aequiv. Kohlensäure und 1 Aequiv. Wasser enthält, also ganz so wie viele natürliche oder künstliche Carbonate zusammengesetzt ist. Diese Art von Bleiweiss besitzt einen hohen Grad ron Vertheilung, und ich fand es in einer dem Auge nicht erkennbaren Art von Suspension in einer wie klar filtrirt scheinenden Flüssigkeit.

In einer solchen Flüssigkeit habe ich die Gegenwart des Bleies nicht auf die gewöhnliche Weise, d. h. mittelst Schwefelwasserstoff, nachgewiesen. Allerdings färben sich durch dieses Reagens die im Wasser suspendirten Partikelchen Bleiweiss an ihrer Oberfläche, allein diese Färbung steht in gar keinem Verhältniss zu der wirklich vorlıandenen Menge der Bleiverbindung. Wenn man dagegen die Vorsicht gebraucht, das zu prüfende $W$ asser vorher mit einigen Tropfen einer Lösung von weinsteinsaurem Ammoniak (einem Salze, welches die Fähigkeit besitzt, unlösliche Bleiverbindungen, wie das Hydrat, Sulphat, Carbonat, Phosphat, Borat, zu lösen) zu versetzen und einige Male aufzukochen, so schlägt nunmehr der Schwefelwasserstoff alles Blei nieder und verursacht dadurch eine nicht zu verkennende dunkle Färbung. Die Reaction wird in dem Grade schwächer, als man das (ursprüngliche) Wasser durch eine Anzahl Papierfilter laufen lässt, ein Beweis, dass die Erscheinung lediglich von einem in Suspension befindlichen Körper herrührt; aber selbst Wasser, welches bereits sieben Filtra passirt hatte, enthielt noch Spuren Blei, erkennbar durch Hülfe des oben angegebenen Verfahrens, 
Dieses Verfahren setzte mich in den Stand festzustellen, dass die Quantitäten gesättigter Solution von schwefelsaurem Kalk in destillirtem $W$ asser, welche von andern Chemikern als die Grenze, bei welcher das Blei nicht mehr angegriffen wird, angegeben sind, sehr bedeutend überschritten waren. Keineswegs hört destillirtes Wasser, welches 4 oder 5 Hundertel gesättigtes Gypswasser enthält, auf, das Blei anzugreifen; es geschieht dieser Angriff auf das Metall selbst durch gesättigte Gypslösung. Allerdings bemerkt man in gesättigter Gypslọsung, worin eine Bleiplatte 24 Stunden lang gelegen hat, nichts vom. Blei; wenn man aber stark schüttelt, um an der Oberfläche des Metalles etwa hängende Theilchen abzuspülen oder einen am Boden befindlichen AbEatz in Suspension zu bringen, so zeigt die Flüssigkeit durch die oben angegebene Behandlung schr augenfallig die Anwesenheit des Bleies. Dicser Versuch, welcher dieselben Resultate liefert, wenn man ihn mit Wasser wiederholt, worin sich andere Solutionen, die wie der Gyps das Blei zu schützen scheinen, befinden, beweist zweierlei: erstens, dass das Blei in den versohiedenen Fällen angegriffen ward, und zweitens dass das Product dieses Angriffs an der Oberfliche des Metalles fest haften blieb. Diese Oberfläche zeigt in der That selbst nach Anwendung der anscheinend conservirendsten Wässer keineswegs mehr den Glanz des frisch geschmolzenen Bleies.

Es handelt sich jetzt darum, zu beweisen, dass dieses Aussehen von einer unlöslichen Bleiverbindung herrübrt. Zu dem Zwecke schabte ich gleich grosse Oberflächen metallisch glänzenden und in gesättigtem Gypswasser matt gewordenen Bleies $a b$, that jede Probe in destillirtes Wasser, welches einige Tropfen weinsteinsaure Ammoniaklösung enthielt, und erhitzte beide Flüssigkeiten zum Sieden. In beiden konnte nun Blei nachgewiesen werden. Obgleich die sine, worin sich das unatt gewordeue Blei befand, weit mehr Metall aufgelöst enthielt, als die andere, und der Zweck des Experiments somit erreicht war, so wünschte ich doch noch entschiedenere l'nterschcidungsmerkmale zu orzielen. Ich operirte daher ein 
zweites Mal, und zwar in der Kälte. Nun wurde das reine Blei ron dem weinsteinsauren Ammoniak weniger, indessen immer noch deutlich angegriffen. $\mathrm{Als}$ ich aber dann eine Flüssigkeit anwandte, aus welcher ich dic Luft durch einige Minuten langes Kochen getrieben hatte, fand ich darin nach der Einwirkung auf reines Blei kein Metall gelöst. Hier fehite also der zur Oxydation des Metalles erforderliche Sauerstoff, während in derjenigen Flüssigkeit, welche unter denselben Umständen (d. i. nach Austreibung der Luft) auf das mit Gypslösung behandelte Metall einwirkte, das weinsteinsaure Ammoniak eine schon fertige Bleiverbindung vorfand, die es bloss aufzulösen brauchte, daher denn auch in dieser Flüssigkeit eine merkliche Menge Blei enthalten war. I.̈̈sst man aber die Flüssigkeit, welche im Kochen von dem reinen Metallo nichts anfgenommen hat, mit dem Metalle erkalten, so findet man schon nach einigen Minuten Blei darin, ein Beweis, mit welcher Schnelligkeit die Luft ihren Einfluss auf das Blei unter der Concurrenz des weinsteinsauren Ammoniaks ausübt und Bleioxyd erzeugt. Aehnliche Versuche mit Bleiplatten, welche in destillirtem Wasser verweilt hatten, das schwefelsaure Alaunerde, schwefelsaure Magnesia, *) doppeltkohlensauren Kalk, einfach - kohlensaures Natron oder doppeltkoblensaures Natron enthielt, lieferten gleiche Rosultate. In allen diesen Fállen war die matte Bleiplatte merklich reiner geworden, ohne jedoch das glänzende Ansehn des frisch geschmolzenen Bleies wieder zu erlangen.

*) Das schwefelsaure Natron schien mir nicht diesolbe Wirksamkcit, wie die erdigen Sulphate, die Aenderung des Bleies zn verl indern, zu hesitzen; das Product, welches dabei entsteht, ist weniger zusammenhängend und trennt sich daher leichter ron dem Metalle. Während dagegen Kochsalz haltiges Wasser auf dem Blei eine continuirliehe, sehwer abtrennbare Schicht erzeugt, bilden die Chloride des Calciums, Magnesiums und Baryums Absätze, welche der Flüssigkeit cin trübes Ansebn ertheilen. 